\section{Retrospective contralateral study comparing Descemet membrane endothelial keratoplasty with Descemet stripping automated endothelial keratoplasty}

A-KB Maier', E Gundlach'1, J Gonnermann'1, MKJ Klamann ${ }^{1}$, E Bertelmann ${ }^{1}$, PW Rieck², AM Joussen ${ }^{1}$ and $\mathrm{N}$ Torun ${ }^{1}$

\begin{abstract}
Purpose In this retrospective study, the visual outcomes and postoperative complications after Descemet stripping automated endothelial keratoplasty (DSAEK) and Descemet membrane endothelial keratoplasty (DMEK) in the fellow eye were compared. The patient's satisfaction was evaluated.

Methods A retrospective analysis of $\mathbf{1 0}$ patients, who underwent DSAEK in one eye and DMEK surgery in their fellow eye, was performed. Intraoperative and postoperative complications were recorded. Visual and refractive outcomes were evaluated, including higher-order aberrations (HOA) and contrast thresholds. A subjective questionnaire was used to evaluate patient satisfaction.

Results Best-corrected visual acuity (BCVA) was significantly better in DMEK when compared with DSAEK $(0.16 \pm 0.10 v s$ $0.45 \pm 0.58 \log$ MAR, $P=0.043)$. Contrast threshold was significantly higher after DMEK than after DSAEK $(0.49 \pm 0.23$ vs $0.25 \pm 0.18, P=0.043)$. Post-keratoplasty astigmatism, mean spherical equivalent, and HOA did not differ. Nine out of ten patients preferred the DMEK procedure. Visual outcome ( $4.80 \pm 1.14$ vs $4.50 \pm 1.58, P=0.257)$, surgery associated pain and burden (DMEK: $1.30 \pm 0.48$ vs DSAEK: $1.30 \pm 0.48, P=1.0$ ), estimated time for recovery and
\end{abstract}

rehabilitation (27.6 \pm 54.0 vs $24.9 \pm 54.8$ days, $P=0.173)$, and mean patient satisfaction (5.40 \pm 0.84 vs $5.00 \pm 1.05, P=0.257)$ were evaluated equally.

Conclusion Patient satisfaction reached high, equal values after DMEK and after DSAEK. Nevertheless, patients preferred DMEK, if given a choice. Reasons for the preference may include better uncorrected and BCVA, and especially a better contrast sensitivity.

Eye (2015) 29, 327-332; doi:10.1038/eye.2014.280; published online 21 November 2014

Introduction

In recent years, Descemet stripping automated endothelial keratoplasty (DSAEK) and Descemet membrane endothelial keratoplasty (DMEK) are increasingly performed in cases of Fuchs endothelial dystrophy and bullous keratopathy. ${ }^{1-10}$ Both procedures are less invasive corneal transplant techniques. In comparison with penetrating keratoplasty main advantages include rapid healing, more predictable refractive outcomes, better corneal integrity, a rapid visual recovery, and fewer postoperative complications. ${ }^{1,4-7,11,12}$

DSAEK procedure was first described by Price and Price. ${ }^{4,7}$ The diseased endothelium
${ }^{1}$ Department of Ophthalmology, CharitéUniversitätsmedizin Berlin, Campus Virchow Klinikum, Charité, Germany

${ }^{2}$ Eye Clinic am Kapellenberg, Potsdam, Germany

Correspondence: A-KB Maier or N Torun, Department of Ophthalmology, CharitéUniversitätsmedizin Berlin, Campus Virchow Klinikum, Augustenburger Platz 1, Berlin 13353, Germany Tel: +49 30450554031 ; Fax: +49 30450554900 . E-mail: anna-karina.maier@ charite.de or necip.torun@charite.de

Received: 23 July 2013 Accepted in revised form: 13 August 2014 Published online: 21 November 2014 
and Descemet membrane are selectively replaced by posterior corneal stroma, Descemet membrane, and endothelium of a donor. ${ }^{4,7}$ In contrast to the DSAEK procedure, in the DMEK procedure, first described by Melles, ${ }^{13}$ an isolated endothelium Descemet membrane layer without adherent corneal stroma is transplanted.

Tourtas et $a l^{1}$ presented the first retrospective study which compared DSAEK and DMEK. In their study, DMEK provided a faster and more complete visual rehabilitation when compared with DSAEK without a significant difference in endothelial cell count. As reasons for these results the thickness of the transplanted lamella and the presence of a stroma lamella in cases of DSAEK are discussed. The stroma lamella seems to be responsible for a posterior astigmatism, a hyperopic shift and altered higher-order optical aberrations resulting in a poorer visual acuity. ${ }^{1,8,14-17}$

Otherwise the DSAEK procedure allows a safer donor preparation and easier manipulation in the anterior chamber because of higher stability of the relatively thick graft. ${ }^{1,18,19}$

These different aspects possibly influence the patient's satisfaction and preference for one or the other surgical procedure. Therefore, we analyzed in our retrospective study the visual and refractive outcome and the patient's satisfaction in a cohort who had undergone DSAEK in one eye and DMEK surgery in their fellow eye.

\section{Materials and methods}

\section{Patients}

We present a retrospective analysis of 10 patients who underwent DSAEK in one eye and DMEK in the fellow eye. Two experienced surgeons (PWR and NT) performed the procedures at the Department of Ophthalmology, Charité-Universitätsmedizin Berlin, Campus Virchow Klinikum. This retrospective study follows the ethical standards of the Declaration of Helsinki. We certify that all applicable institutional and governmental regulations concerning the ethical use of human volunteers were followed during this research.

\section{Preoperative and postoperative evaluation}

Clinical evaluation included best-corrected visual acuity (BCVA), slit-lamp examination, applanation tonometry (Goldmann applanation tonometer, Haag Streit, Bern, Switzerland), and funduscopy, preoperatively and 2 and 4 weeks, and 3, 6, 12, and 24 months after DSAEK or DMEK. Distant visual acuity was tested with a Snellen chart and expressed as a Snellen decimal number. For the purposes of statistical analysis, the Snellen decimal number was converted to logMAR using a Visual acuity Conversion Table. ${ }^{20}$ Additionally, data on uncorrected visual acuity (UCVA), contrast threshold (Mesoptometer II, Oculus Optikgeräte GmbH, Wetzlar, Germany), preoperative and postoperative refraction, corneal topography, higher-order aberrations (HOA; total root mean square (RMS), second, third, and fourth order aberrations; Galilei dual scheimpflug analyzer, V5.2.1, Ziemer Ophthalmic Systems AG, Port, Switzerland), and endothelial cell counts (NONCON-ROBO CA specular microscope, KONAN MEDICAL INC., Nishinomiya, Japan) were collected. All these parameters, except contrast threshold measurement, corneal topographies, and HOA were measured preoperatively and at the last follow-up visit. Contrast threshold was measured by presenting an isolated Landolt ring of variable contrast. The lowest contrast at which the Landolt ring was identified correctly was analyzed and the contrast ratio background: Landolt ring was noted. On the last follow-up visit, a patient's questionnaire was presented to the patients. The questionnaire included questions grading the symptoms and overall satisfaction with surgery on a scale of 1-6 (Supplementary Data, patient's questionnaire). ${ }^{8}$

\section{Graft and surgical techniques}

Cultured grafts with a minimum central endothelial density of $2000 / \mathrm{mm}^{2}$ from the Cornea Bank Berlin were used for transplantation.

In all cases clear corneal incisions were used. In cases of additional cataract a combined procedure (Triple DSAEK or Triple DMEK) with DSAEK or DMEK following standard cataract surgery was performed.

In nine eyes before DMEK surgery and in five eyes before DSAEK surgery, significant lens opacity was present and a combined procedure with DMEK or DSAEK following phacoemulsification and posterior chamber intraocular lens implantation was performed.

\section{DSAEK}

The DSAEK surgical technique was performed in a minimally modified manner described in detail by Price and Price. 4,7,21 The donor graft was dissected using either the Moria ALTK system (Moria/Microtek Inc., Doylestown, PA, USA) or the Schwind Carriazo pendular microkeratome (SCHWIND eye-tech-solutions $\mathrm{GmbH} \&$ Co. KG, Kleinostheim, Germany). Attempted donor lamella depth was from 100 to $200 \mu$ m (mean $154.9 \pm 48.9 \mu \mathrm{m})$. The maximum diameter of the graft was $8.5 \mathrm{~mm}$.

Standard postoperative topical treatment included a combination of steroid (three to five times daily) and lubricant eye drops (five times daily) in combination with a combined antibiotic and steroid ointment at night. During the first days, pilocarpine eye drops (1\%) were 
given until the air bubble was absorbed. After 1 week, the ointment was stopped and prednisolone acetate $1 \%$ was used topically (three times daily for the first 3 months) with lubricant eye drops five times daily. The prednisolone acetate $1 \%$ was tapered down over a period of 2-3 months to once or twice daily, and patients remained on this dosage until 1 year postoperatively unless they developed steroid-induced glaucoma.

\section{DMEK}

Stripping of the endothelial Descemet membrane from the donor corneal stroma was performed immediately prior to transplantation in a standardized manner described in detail by Melles et al. ${ }^{13,22,23}$ The diameter of the graft ranges between 8.5 and $9.0 \mathrm{~mm}$ with an incision of $2.75 \mathrm{~mm}$.

Standard postoperative topical treatment included a combination of steroid (three times daily) and lubricant eye drops (five times daily) in combination with a combined antibiotic and steroid ointment overnight. After 1 week, the ointment was stopped and prednisolone acetate $1 \%$ was used topically (three times daily for the first 3 months) with lubricant eye drops five times daily. The prednisolone acetate $1 \%$ was tapered down over a period of 2-3 months to once daily, and patients remained on this dosage until 1 year postoperatively unless they developed steroid-induced glaucoma.

\section{Statistical methods}

The statistical analysis was performed using IBM SPSS statistics 19 (SPSS Software, Munich, Germany). Descriptive statistics were expressed as median and range between minimum and maximum, or mean \pm SD. Paired data were collected. Normal distribution could not be determined for all outcome measures. Therefore, paired nonparametric (Wilcoxon) testing was used for analysis of continuous variables. For analyzing the distribution of proportions, a $\chi^{2}$ distribution was used. Differences were considered statistically significant when $P$-values were $<0.05$.

\section{Results}

In this study we included 20 eyes of 10 patients (4 female and 6 male). The mean age of patients was $71 \pm 6$ years.
Underlying disease was Fuchs dystrophy in all cases. In all patients, DSAEK surgery in one eye and DMEK surgery in their fellow eye were performed. Fourteen cases had a combined procedure (DMEK or DSAEK and standard cataract surgery).

Preoperative data and the follow-up time for both study groups are summarized in Table 1, the postoperative results at the last follow-up after DSAEK vs DMEK are summarized in Table 2.

\section{Visual acuity and refraction}

Visual acuity improved after DSAEK and significantly after DMEK surgery at the last follow-up compared with preoperatively ( $P=0.09, P<0.01$; Table 2$)$. At the last follow-up the BCVA and UCVA (logMAR) were significantly better in DMEK than in DSAEK $(P=0.043$, $P=0.057)$.

Evaluation of contrast threshold was not possible in two patients due to defective device. Mean contrast ratio background: Landolt ring of the measured data is presented in Table 2. All patients demonstrated a better contrast ratio in the DMEK operated eye than in the DSAEK operated eye. Difference was statistically significant $(P=0.043)$.

The mean manifest spherical equivalent and the mean manifest cylinder did not differ significantly between DSAEK and DMEK ( $P=0.725, P=0.436$; Table 2$)$.

The data of wavefront analysis of HOA (with a 6-mm pupil diameter) are shown in Table 2. Data of one eye after DSAEK were excluded from the statistical analysis because the quality of HOA measurements was too low to analyze. Total RMS, second, third, and fourth order aberrations demonstrated no significant different results between eyes after DMEK and eyes after DSAEK ( $P=0.767, P=0.0953, P=0.635, P=0.953)$.

\section{Complications}

Various mild complications occurred in both groups.

Additional application of intracameral air was used in five cases after DMEK $(50 \%)$ and in one case after DSAEK $(10 \%)$ to re-fix graft detachments. In one case post-DMEK (10\%) and no case post-DSAEK, intraocular pressure was raised on the first

Table 1 Characteristics of the patients

\begin{tabular}{lccc}
\hline & DSAEK $(\mathrm{n}=10)$ & DMEK $(\mathrm{n}=10)$ & P-values \\
\hline Follow-up time (months) & $21.0 \pm 10.5$ & $6.5 \pm 3.2$ & 0.005 \\
Preoperative BCVA (logMAR) & $0.60 \pm 0.16$ & $0.60 \pm 0.18$ & 1.000 \\
Manifest SE & $0.74 \pm 2.00$ & $-0.76 \pm 2.06$ & 0.207 \\
Manifest cylinder & $1.53 \pm 1.03$ & $0.97 \pm 0.83$ & 0.203 \\
Preoperative endothelial cell number $\left(1 / \mathrm{mm}^{2}\right)$ & $2316 \pm 233$ & $2369 \pm 260$ & 0.575 \\
\hline
\end{tabular}


Table 2 Postoperative results at the last follow-up after DSAEK vs DMEK

\begin{tabular}{|c|c|c|c|}
\hline & $D S A E K(\mathrm{n}=10)$ & $D M E K(\mathrm{n}=10)$ & P-values \\
\hline BCVA (logMAR) & $0.45 \pm 0.58$ & $0.16 \pm 0.10$ & 0.043 \\
\hline UCVA (logMAR) & $0.64 \pm 0.53$ & $0.36 \pm 0.17$ & 0.057 \\
\hline Manifest SE & $0.26 \pm 0.67$ & $-0.11 \pm 1.14$ & 0.725 \\
\hline Manifest cylinder & $1.83 \pm 1.02$ & $1.63 \pm 0.64$ & 0.436 \\
\hline Contrast threshold (contrast ratio background: Landolt ring) & $0.25 \pm 0.18$ & $0.49 \pm 0.23$ & 0.043 \\
\hline \multicolumn{4}{|l|}{ Wavefront analysis } \\
\hline Root mean square total $(\mu \mathrm{m})$ & $1.93 \pm 0.86$ & $1.69 \pm 0.77$ & 0.767 \\
\hline Astigmatism (D) & $1.61 \pm 0.58$ & $1.27 \pm 0.82$ & 0.441 \\
\hline Second order aberration $(\mu \mathrm{m})$ & $1.45 \pm 0.78$ & $1.29 \pm 0.65$ & 0.953 \\
\hline Third order aberration $(\mu \mathrm{m})$ & $0.90 \pm 0.32$ & $0.79 \pm 0.33$ & 0.635 \\
\hline Fourth order aberration $(\mu \mathrm{m})$ & $0.50 \pm 0.26$ & $0.46 \pm 0.21$ & 0.953 \\
\hline Endothelial cell number after 6 months $\left(1 / \mathrm{mm}^{2}\right)$ & $1053 \pm 303(n=4)$ & $1914 \pm 519(n=6)$ & 0.109 \\
\hline
\end{tabular}

postoperative day as a result of air bubble-induced mechanical angle closure. Steroid-induced intraocular pressure elevation occurred 3 months postoperatively in two eyes after DSAEK and one eye after DMEK. To bridge intraocular pressure elevation during tapering down the local steroids, patients were treated successfully with topical antiglaucomatous medications. Additionally, cataract surgery was performed after half a year in one eye post-DSAEK. No immune rejection was observed during follow-up in any of the groups.

\section{Results of questionnaire}

Three out of 10 patients (30\%) evaluated their visual outcome post surgery as superior in the DMEK eye than in the DSAEK eye, and one the other way around (question 1, Supplementary Data, patient's questionnaire). There was no significant difference in grading the visual outcomes after DMEK and after DSAEK (DMEK:

$4.80 \pm 1.14$ vs DSAEK: $4.50 \pm 1.58, P=0.257)$.

With regard to surgery associated pain and burden (question 2, Supplementary Data, patient's questionnaire), no patient (0\%) noted a difference between either procedures. All patients evaluated both procedures equal with less associated pain and burden (DMEK: $1.30 \pm 0.48$ vs DSAEK: $1.30 \pm 0.48, P=1.0$ ).

The estimated time for recovery and rehabilitation (question 3, Supplementary Data, patient's questionnaire) showed no difference between DSAEK (27.6 \pm 54.0 days) and DMEK ( $24.9 \pm 54.8$ days; $P=0.173)$.

Mean patient satisfaction was high after both procedures with no significant difference (DMEK: $5.40 \pm 0.84$ vs DSAEK: $5.00 \pm 1.05, P=0.257$; question 4 , Supplementary Data, patient's questionnaire).

When asked about their preferred surgical procedure, eight patients (80\%) preferred DMEK. Only two patients preferred DSAEK over DMEK.

\section{Discussion}

In the present study, we directly compared the functional results of DMEK with those of DSAEK in individual patients. Moreover, the patient's perception was evaluated.

Our data support previous studies that compared DMEK and DSAEK. Visual acuity was significantly better following DMEK compared with DSAEK.1,6,10,24-26 Other studies suggest that the stroma lamella is responsible for a posterior astigmatism, a hyperopic shift and altered higher-order optical aberrations after DSAEK. 1,8,14-17,27 In our study, we found no difference in total HOA, astigmatism, and spherical equivalent between DSAEK and DMEK. In both groups, changes in mean spherical equivalent and astigmatism were small. ${ }^{28}$ In our study, these shifts tended toward myopia for DSAEK and toward hyperopia for DMEK, a finding in contrast to data from other DSAEK studies and in accordance to data from other DMEK studies. 8,28

In addition to the better visual acuity outcomes after DMEK than after DSAEK, the contrast thresholds were significantly increased after DMEK when compared with DSAEK. These results support data reported by Bahar et $a l_{,}^{8}$ who demonstrated better contrast thresholds after penetrating keratoplasty than after DSAEK. The presence of stroma following DSAEK, and therefore the thickness of the transplanted lamella and the stroma-stroma interface, may explain the worse contrast sensitivity and the poorer visual acuity.

In one eye we already replaced a DSAEK graft with DMEK because of poor visual result after DSAEK as suggested by Ham et al. ${ }^{29}$

Rate of complications was low after both procedures. As described by many authors the risk of postoperatively graft detachment is higher after DMEK than after DSAEK. 10,18,19 Therefore, a higher rate of air-injections was necessary in eyes after DMEK (50\%) than after 
DSAEK (10\%). In accordance with other studies, long-term complications (eg, persistent epithelial defects, intraocular pressure elevation, post-keratoplasty glaucoma, and graft failure after immune rejection) were hardly registered. Steroid-induced intraocular pressure elevation occurred most frequently, $11,30,31$ but treated successfully in all cases.

In both groups, endothelial cell numbers decreased significantly between preoperative and postoperative graft measurements. ${ }^{1,5,10,32}$ Endothelial cell loss was comparable between DSAEK and DMEK after 6 months postoperatively. 1,10

The results from our patient questionnaire demonstrate that almost all patients preferred DMEK, if given a choice. Although visual outcomes, time for recovery and rehabilitation, surgery associated pain and burden, and mean patient satisfaction were all rated equal after DMEK and after DSAEK, the better functional outcome is probably decisive for choice. Apparently, the decision appears not to be influenced by the more frequent need of air-injection in the early postoperative period after DMEK than after DSAEK. Overall, patient satisfaction reached high values for both procedures.

In this intraindividual comparative study, the main limitations were the small sample size, the retrospective character, and the differing follow-up times after each procedure. ${ }^{8}$ In particular, the differing follow-up times may lead to a recall bias in the patient satisfaction questionnaire. Probably more detailed prospective studies should be initiated.

In conclusion, patient satisfaction reached high, equal values after both procedures. Nevertheless, patients preferred DMEK, if given a choice. Reasons for the preference may include: better uncorrected and BCVA and especially a better contrast sensitivity.

\section{Summary}

\section{What was known before}

- Tourtas et al presented the first retrospective study that compared Descemet stripping automated endothelial keratoplasty (DSAEK) and Descemet membrane endothelial keratoplasty (DMEK). In their study DMEK provided a faster and more complete visual rehabilitation when compared with DSAEK. As reasons for these results, the thickness of the transplanted lamella and the presence of a stroma lamella in cases of DSAEK are discussed. The stroma lamella seems to be responsible for a posterior astigmatism, a hyperopic shift and altered higher-order optical aberrations resulting in a poorer visual acuity.

\section{What this study adds}

- The present study compares directly the results of DMEK with DSAEK in individual patients according to visual acuity, astigmatism, mean spherical equivalent, highorder aberrations, and especially contrast treshold. Furthermore, the patient's satisfaction was evaluated.

\section{Conflict of interest}

The authors declare no conflict of interest.

\section{Acknowledgements}

A-KBM: financial support provided by the 'Friedrich $\mathrm{C}$. Luft' Clinical Scientist Pilot Program funded by Volkswagen Foundation and Charité Foundation. EG: financial support provided by the 'Ernst und Bertha Grimmke Stiftung'.

\section{References}

1 Tourtas T, Laaser K, Bachmann BO, Cursiefen C, Kruse FE. Descemet membrane endothelial keratoplasty versus descemet stripping automated endothelial keratoplasty. Am J Ophthalmol 2012; 153: 1082-1090.

2 Droutsas K, Ham L, Dapena I, Geerling G, Oellerich S, Melles G. [Visual acuity following Descemet-membrane endothelial keratoplasty (DMEK): first 100 cases operated on for Fuchs endothelial dystrophy]. Klin Monbl Augenheilkd 2010; 227: 467-477.

3 Guerra FP, Anshu A, Price MO, Giebel AW, Price FW. Descemet's membrane endothelial keratoplasty: prospective study of 1-year visual outcomes, graft survival and endothelial cell loss. Ophthalmology 2011; 118: 2368-2373.

4 Price Jr FW, Price MO. Descemet's stripping with endothelial keratoplasty in 50 eyes: a refractive neutral corneal transplant. J Refract Surg 2005; 21: 339-345.

5 Terry MA, Shamie N, Chen ES, Hoar KL, Friend DJ. Endothelial keratoplasty a simplified technique to minimize graft dislocation, iatrogenic graft failure, and pupillary block. Ophthalmology 2008; 115: 1179-1186.

6 Gorovoy MS. Descemet-stripping automated endothelial keratoplasty. Cornea 2006; 25: 886-889.

7 Price Jr FW, Price MO. Descemet's stripping with endothelial keratoplasty in 200 eyes: early challenges and techniques to enhance donor adherence. J Cataract Refract Surg 2006; 32: 411-418.

8 Bahar I, Kaiserman I, Levinger E, Sansanayudh W, Slomovic AR, Rootman DS. Retrospective contralateral study comparing descemet stripping automated endothelial keratoplasty with penetrating keratoplasty. Cornea 2009; 28: 485-488.

9 Yoeruek E, Bayyoud T, Röck D, Szurman P, Bartz-Schmidt KU. [Clinical results after Descemet membrane endothelial keratoplasty]. Klin Monbl Augenheilkd 2012; 229: 615-620.

10 Guerra FP, Anshu A, Price MO, Price FW. Endothelial keratoplasty: fellow eyes comparision of Descemet stripping automated endothelial keratoplasty and Descemet membrane endothelial keratoplasty. Cornea 2011; 30: 1382-1386.

11 Vajaranant TS, Price MO, Price FW, Gao W, Wilensky JT, Edward DP. Visual acuity and intraocular pressure after Descemet's stripping endothelial keratoplasty in eyes with and without preexisting glaucoma. Ophthalmology 2009; 116: 1644-1650.

12 Anshu A, Price MO, Price Jr. FW. Risk of corneal transplant rejection significantly reduced with Descemet's membrane endothelial keratoplasty. Ophthalmology 2012; 119: 536-540. 
13 Melles GR, Ong TS, Ververs B, van der Wees J. Descemet membrane endothelial keratoplasty (DMEK). Cornea 2006; 25: 987-990.

14 Bahar I, Kaiserman I, Livny E, Slomovic A, Slomovic A. Changes in corneal curvatures and anterior segment parameters after descemet stripping automated endothelial keratoplasty. Curr Eye Res 2010; 35: 961-966.

15 Rudolph M, Laaser K, Bachmann BO, Cursiefen C, Epstein D, Kruse FE. Corneal higher-order aberrations after Descemet's membrane endothelial keratoplasty. Ophthalmology 2012; 119: 528-535.

16 Scorcia V, Matteoni S, Scorcia GB, Scorcia G, Busin M. Pentacam assessment of posterior lamellar grafts to explain hyperopization after Descemet's stripping automated endothelial keratoplasty. Ophthalmology 2009; 116: 1651-1655.

17 Lombardo M, Terry MA, Lombardo G, Boozer DD, Serrao S, Ducoli P. Analysis of posterior donor corneal parameters 1 year after Descemet stripping automated endothelial keratoplasty (DSAEK) triple procedure. Graefes Arch Clin Exp Ophthalmol 2010; 248: 421-427.

18 Busin M, Bhatt PR, Scorcia V. A modified technique for descemet membrane stripping automated endothelial keratoplasty to minimize endothelial cell loss. Arch Ophthalmol 2008; 126: 1133-1137.

19 Khor WB, Mehta JS, Tan DT. Descemet stripping automated endothelial keratoplasty with a graft insertion device: surgical technique and early clinical results. Am J Ophthalmol 2011; 151: 223-232.

20 Joussen AM, Heussen FM, Joeres S, Llacer H, Prinz B, Rohrschneider $\mathrm{K}$ et al. Autologous translocation of the choroid and retinal pigment epithelium in age-related macular degeneration. Am J Ophthalmol 2006; 142: 17-30.

21 Price MO, Price Jr FW. Descemet's stripping with endothelial keratoplasty: comparative outcomes with microkeratome-dissected and manually dissected donor tissue. Ophthalmology 2006; 113(11): 1936-1942.

22 Melles GR, Ong TS, Ververs B, van der Wees J. Preliminary clinical results of Descemet membrane endothelial keratoplasty. Am J Ophthalmol 2008; 145: 222-227.
23 Lie JT, Birbal R, Ham L, van der Wees J, Melles GR. Donor tissue preparation for Descemet membrane endothelial keratoplasty. J Cataract Refract Surg 2008; 34: 1578-1583.

24 Ham L, Balachandran C, Verschoor CA, van der Wees J, Melles GR. Visual rehabilitation rate after isolated descemet membrane transplantation: descemet membrane endothelial keratoplasty. Arch Ophthalmol 2009; 127: 252-255.

25 Price MO, Giebel AW, Fairchild KM, Price Jr FW. Descemet's membrane endothelial keratoplasty: prospective multicenter study of visual and refractive outcomes and endothelial survival. Ophthalmology 2009; 116: 2361-2368.

26 Koenig SB, Covert DJ, Dupps Jr WJ, Meisler DM. Visual acuity, refractive error, and endothelial cell density six months after Descemet stripping and automated endothelial keratoplasty (DSAEK). Cornea 2007; 26: 670-674.

27 Muftuoglu O, Prasher P, Bowman RW, McCulley JP, Mootha VV. Corneal higher-order aberrations after Descemet's stripping automated endothelial keratoplasty. Ophthalmology 2010; 117: 878-884.

28 Ham L, Dapena I, Moutsouris K, Balachandran C, Frank LE, van Dijk K et al. Refractive change and stability after Descemet membrane endothelial keratoplasty. Effect of corneal dehydration-induced hyperopic shift on intraocular lens power calculation. J Cataract Refract Surg 2011; 37: 1455-1464.

29 Ham L, Dapena I, van der Wees J, Melles GR. Secondary DMEK for poor visual outcome after DSEK: donor posterior stroma may limit visual acuity in endothelial keratoplasty. Cornea 2010; 29: 1278-1283.

30 Maier AK, Klamann MK, Torun N, Gonnermann J, Schroeter J, Joussen AM et al. Intraocular pressure elevation and post-DSEK glaucoma after Descemet's stripping endothelial keratoplasty. Graefes Arch Clin Exp Ophthalmol 2013; 251: 1191-1198.

31 Naveiras M, Dirisamer M, Parker J, Ham L, van Dijk K, Dapena I et al. Causes of glaucoma after descemet membrane endothelial keratoplasty. Am J Ophthalmol 2012; 153: 958-966.

32 Ham L, van Luijk C, Dapena I, Wong TH, Birbal R, van der Wees $\mathrm{J}$ et al. Endothelial cell density after descemet membrane endothelial keratoplasty: 1- to 2-year follow-up. Am J Ophthalmol 2009; 148: 521-527.

Supplementary Information accompanies this paper on Eye website (http://www.nature.com/eye) 